\title{
Ocultamiento de sestercios altoimperiales y sítula de bronce en Santa Fe de Mondújar (Almería)
}

\section{A set of Imperial sesterces and bronze situla from Santa Fe de Mondújar (Almería)}

\author{
Bartolomé Mora Serrano \\ Universidad de Málaga \\ barmora@uma.es \\ ORCID iD: https://orcid.org/0000-0002-0909-9225 \\ Salvador F. Pozo \\ Arqueólogo \\ salvafpozo1@gmail.com \\ ORCID iD: https://orcid.org/0000-0003-0902-1812
}

Enviado: 28-03-2020. Aceptado: 01-09-2020. Publicado online: 22-06-2021

Cómo citar este artículo / Citation: Mora Serrano, B. y Pozo, S. F. (2021). "Ocultamiento de sestercios altoimperiales y sítula de bronce en Santa Fe de Mondújar (Almería)". Archivo Español de Arqueología, 94, e11. DOI: https://doi.org/10.3989/aespa.094.021.11

RESUMEN: Aunque son escasos los hallazgos monetarios de estas características en el actual territorio almeriense, es su asociación a una sítula de bronce, en muy buen estado de conservación, lo que otorga un mayor interés a este ocultamiento de Santa Fe de Mondújar. A pesar de su modesto número -14 ejemplares- este hallazgo insiste en la cada vez más acusada presencia del sestercio en la circulación monetaria hispana desde la segunda mitad del siglo I d. C. -aquí representado por el sestercio de Vespasiano- hasta finales del siglo II d. C. En este caso las emisiones de Trajano-Adriano y los primeros Antoninos ocupan un papel muy destacado, mientras las emisiones de Antonino Pío y Marco Aurelio tienen una menor representación, pero equilibrada, con dos ejemplares cada uno. Por otro lado, esta singular asociación contribuye a la mejor datación de este tipo de sítula de bronce -Radnóti (1938) XI, 57-, a la vez que permite profundizar en las posibles causas de su ocultamiento.

Palabras clave: hallazgo monetario (tesorillo); sestercios; altoimperio; sítula de bronce; Almería.

\begin{abstract}
Although monetary finds of these nature are scarce in the territory of Almeria today, it is their association with a bronze situla, in a very good state of conservation, which gives greater interest to this hiding place in Santa Fe de Mondújar. Despite its modest number-14 coins - this finding insists on the increasingly marked presence of sesterce in Hispanic monetary circulation since the second half of the first century AD - here represented by Vespasian sesterce - until the end of the 2nd century AD. In this case the issues of Trajan-Adrianus and the early Antonines play a very important role, while the issues of Antoninus Pius and Marcus Aurelius are less represented, but equally represented, with two copies each. On the other hand, this unique association contributes to the best dating of the type of situla-Radnóti XI, 57-, while allowing us to go deeper into the possible causes of its occultation.
\end{abstract}

Keywords: coin horad; sestertius; Hispania Baetica; Almería; Roman bronze situla.

Copyright: ( 2021 CSIC. Este es un artículo de acceso abierto distribuido bajo los términos de la licencia de uso y distribución Creative Commons Reconocimiento 4.0 Internacional (CC BY 4.0). 
El 10 de mayo de 2017 ingresó en el Museo de Almería un conjunto de catorce monedas romanas, doce sestercios y dos dupondios, junto con un recipiente de bronce que las contenía. Dicho hallazgo fortuito data de los años 70 del siglo pasado, y en el acta de entrega de dichos objetos arqueológicos, en forma de donación por uno de los herederos de su antiguo propietario, consta como procedencia de este ocultamiento el paraje conocido como "Fuente del Rey", en el término municipal de la localidad almeriense de Santa Fe de Mondújar. Gracias a la colaboración del Servicio de Bienes Culturales de la Junta de Andalucía en Almería, es posible vincular este lugar con el yacimiento arqueológico de La Quinta, una villa romana de larga ocupación y cierta entidad que no ha sido objeto de intervenciones arqueológicas (Cara y Carrilero, 1987, pp. 65-66; López Medina, 2004, p. 375). La presentación y estudio de este interesante hallazgo se debe a la generosa donación de su último propietario, al celo del personal del Área de Medio Ambiente de la Junta de Andalucía en Almería y, desde luego, a la amabilidad de la dirección y conservadores del Museo Arqueológico de la capital almeriense.

Aunque, en efecto, se trata de un hallazgo sin contexto arqueológico, y por tanto carente de una información siempre importante y en ocasiones vital para su correcto estudio e interpretación, el conjun- to de monedas altoimperiales, doce sestercios y dos dupondios, junto a la sítula de bronce que aquí se dan a conocer reviste no poco interés para la arqueología romana almeriense $\mathrm{y}$, desde luego también, para la circulación monetaria romana de época altoimperial en el sureste de la Península Ibérica. No obstante, debemos ser conscientes de las serias limitaciones que se derivan de las circunstancias de este hallazgo en lo que concierne al número y distribución cronológica de las monedas que aparecieron junto a la sítula. Pero, precisamente, la conservación de este vaso de bronce, de mucho más valor de mercado que las monedas, permite suponer -sin total seguridad- que este singular hallazgo ha podido llegar íntegro hasta nosotros.

\section{EL LUGAR DEL HALLAZGO: UN POSIBLE ASENTAMIENTO RURAL DE ÉPOCA ALTOIMPERIAL EN EL BAJO ANDARAX}

El término municipal de Santa Fe de Mondújar, bien conocido por localizarse allí el famoso yacimiento de Los Millares, forma parte de la comarca almeriense del Bajo Andarax, cuyo eje vertebrador es el río que le da nombre. Su condición de principal eje natural de comunicaciones entre la costa del golfo almeriense y el Portus Magnus (Almería) con la Hoya de Guadix y la antigua $A c c i$ queda sancionada en la red viaria

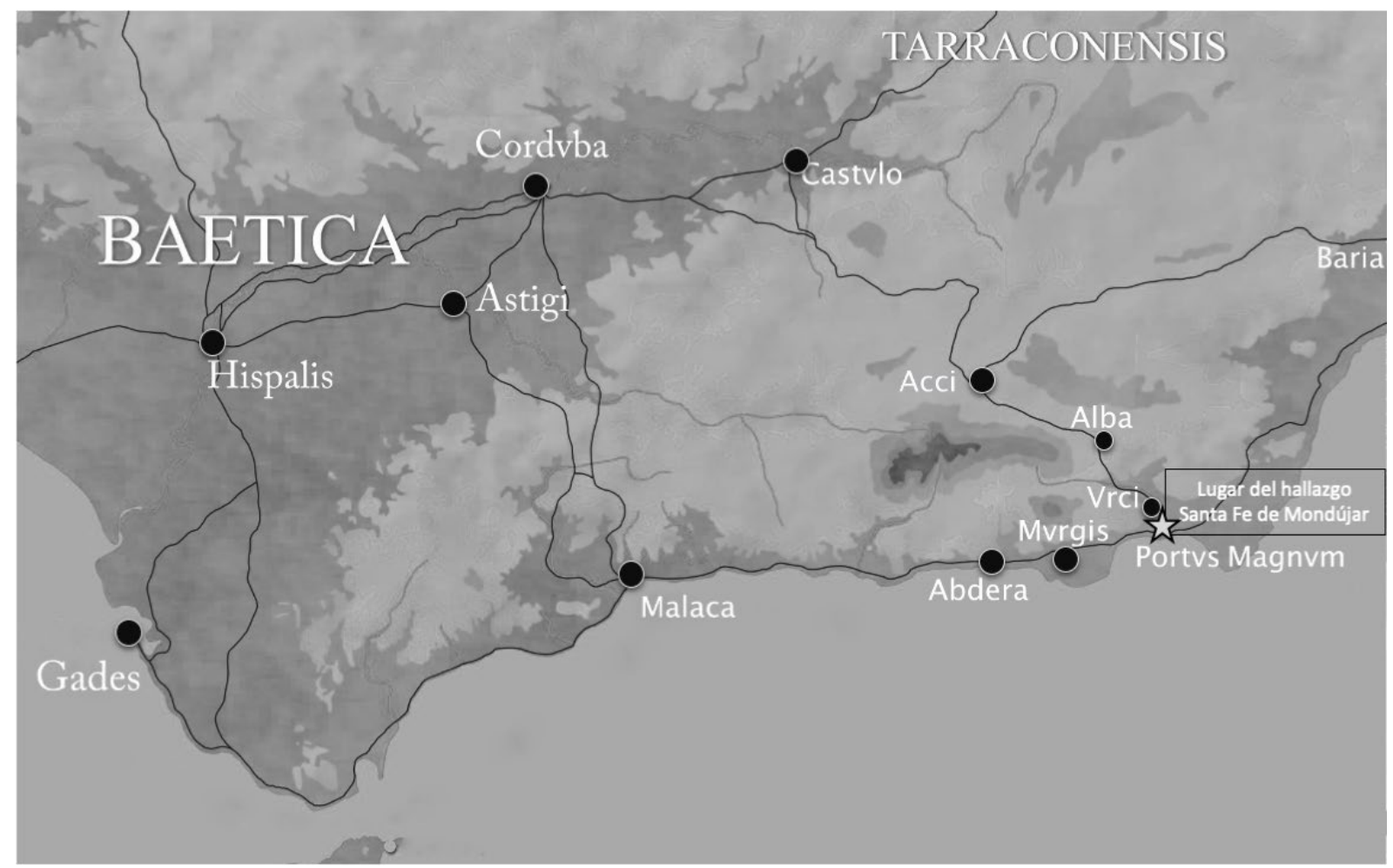

Figura 1. Localización de Santa Fe de Mondújar en la zona suroriental de la Bética (elaboración propia). 
romana del sureste hispano (Sillières, 1990, pp. 339 ss, 396; Corzo y Toscano, 1992, p. 165), aunque en una posición secundaria con respecto a los itinerarios principales como la vía Castulo-Malaca y, también, la que enlazaba con Baria (Villaricos) a través del pasaje de Fiñana, en conexión con la antigua localidad de AlbalAlbatha (Ortiz Ocaña, 2016, pp. 81-94; Álvarez Martín, 2013, pp. 58-61) (Fig. 1).

El paraje conocido como Fuente del Rey, se sitúa en la confluencia de la Rambla de Huéchar y la antigua carretera de Alhama de Almería, algo alejado del río Andarax y también del camino que conducía desde la costa a Urci, ya citado. Muy poco es lo que conocemos de este posible asentamiento romano, por el momento solo sustentado por el hallazgo fortuito de la sítula de bronce con el conjunto de monedas altoimperiales que aquí se estudian. No obstante, parece encajar con otros enclaves de similares características localizados en el transcurso de prospecciones llevadas a cabo desde los años ochenta del pasado siglo en este singular entorno geográfico, potenciado por su condición de corredor natural interior-costa y, especialmente también, por las cercanas explotaciones mineras de la Sierra de Gádor y la fertilidad de las pequeñas vegas próximas al río Andarax (Cara y Carrilero, 1987 p. 65), o de manantiales como es nuestro caso. Puede que vinculado al territorium del antiguo oppidum ibérico y posterior municipio romano de Urci (El Chuche, Benahadux, Almería), además de La Quinta conocemos otros yacimientos romanos dentro del actual término municipal de Santa Fe de Mondújar, que se complementan con otros cercanos de cierta entidad en algunos casos como Cerro de Nicolás Godoy, Huéchar, Loma del Toro o Alhama, mientras que otros son más bien modestos establecimientos rurales situados en sitios aislados o peor comunicados (López Medina, 2004, pp. 133-135, 375).

\section{EL CONTENEDOR: SÍTULA ALTOIMPERIAL DE BRONCE (TIPO RADNÓTI, 1938, XI, 57)}

Además del interés de las monedas que forman parte de este hallazgo, por ser uno de los pocos ejemplos de este tipo de ocultamientos monetarios hispanos, y el único del territorio almeriense, su asociación a una sítula de bronce en buen estado de conservación, que incluye además su asa y apliques de sujeción, permiten calificarlo de singular. Como es bien conocido, lo habitual en este tipo de ocultamientos monetarios es que su modesto contenedor, si es que lo hubo, no se haya conservado al tratarse de materiales perecederos como saquitos de tela o piel, que en algunas ocasiones reconocemos de forma indirecta gracias al proceso de oxidación de las monedas. En otros casos, incluso aso- ciados a ocultamientos monetarios de mayor número y valor, son los recipientes cerámicos los contenedores más socorridos. Por ello, un vaso metálico como el que a continuación se describe es raro en los hallazgos monetarios hispanos documentados de época altoimperial $^{1}$; y más aún si atendemos a su modesto contenido numismático. Sin embargo, en las provincias nororientales y danubianas del Imperio esta asociación sí está bien constatada, como se desprende del estudio de J. Gorecki en el que se recogen 139 hallazgos de vasos metálicos como contenedores de monedas, con predominio de las formas cerradas - tipos Radnóti 75, $77-81$ y 83 - sobre las abiertas como calderos y sítulas - tipos Radnóti 51, 53, 56 y 57 - (Gorecki, 1991, pp. 210-211 y Tab. 2). Este tipo de hallazgos mixtos están mejor documentados en el siglo III d.C. y en todos los casos son raros los que incluyen monedas de bronce y en escaso número (Gorecki, 1991, p. 229, n 132).

El término sítula -situla- designa los recipientes cónicos o cilíndricos cuyo diámetro -normalmentees superior a su altura en oposición a los calderos cuyo diámetro de abertura es inferior a su altura. Otra diferencia es la base plana o circular que está ausente en los calderos ya que estos cuelgan con una cadena sobre el fuego y su base es ligeramente convexa e incluso redondeada. La sítula de Santa Fe de Mondújar es de pequeñas dimensiones $(\mathrm{H} 12,9 \mathrm{~cm}$; D abertura $21 \mathrm{~cm}$ ), realizada mediante fusión y retoques a torno y aunque está siendo sometida a un proceso de limpieza y restauración su estado actual permite una descripción bastante precisa (Fig. 2).

Su perfil es acampanado, con las paredes cóncavas en la zona central y abombadas hacia la base. Tiene un pie anular, bajo, estrecho y algo rehundido, señalado con una moldura, y círculos concéntricos en el reverso. El cuerpo está decorado con parejas de finas ranuras. El borde es resaltado y exvasado, de labio corto y oblicuo. El asa es redondeada e irregular, se curva en sus extremos para insertarse en el orificio del aplique inferior -pieza independiente elaborada a partir de una lámina de metal, recortada y soldada posteriormente a la pared del vaso- que reproduce un motivo fitomorfo y cuoriforme. Pertenece al grupo de apliques no figurados -Tipo B II de la clasificación de Delgado (1970)- de menor visibilidad en las publicaciones sobre este tipo de materiales, en contraste con los estu-

1 En época romanorrepublicana son conocidos los hallazgos de moneda y vasos metálicos junto a otro tipo de manufacturas (Villaronga, 1993; o Gozalbes y Torregrosa, 2014, pp. 282, 286). En nuestro catálogo se cita el de Villanueva de Córdoba, pero queda muy lejos en cronología y composición del que aquí se estudia. 


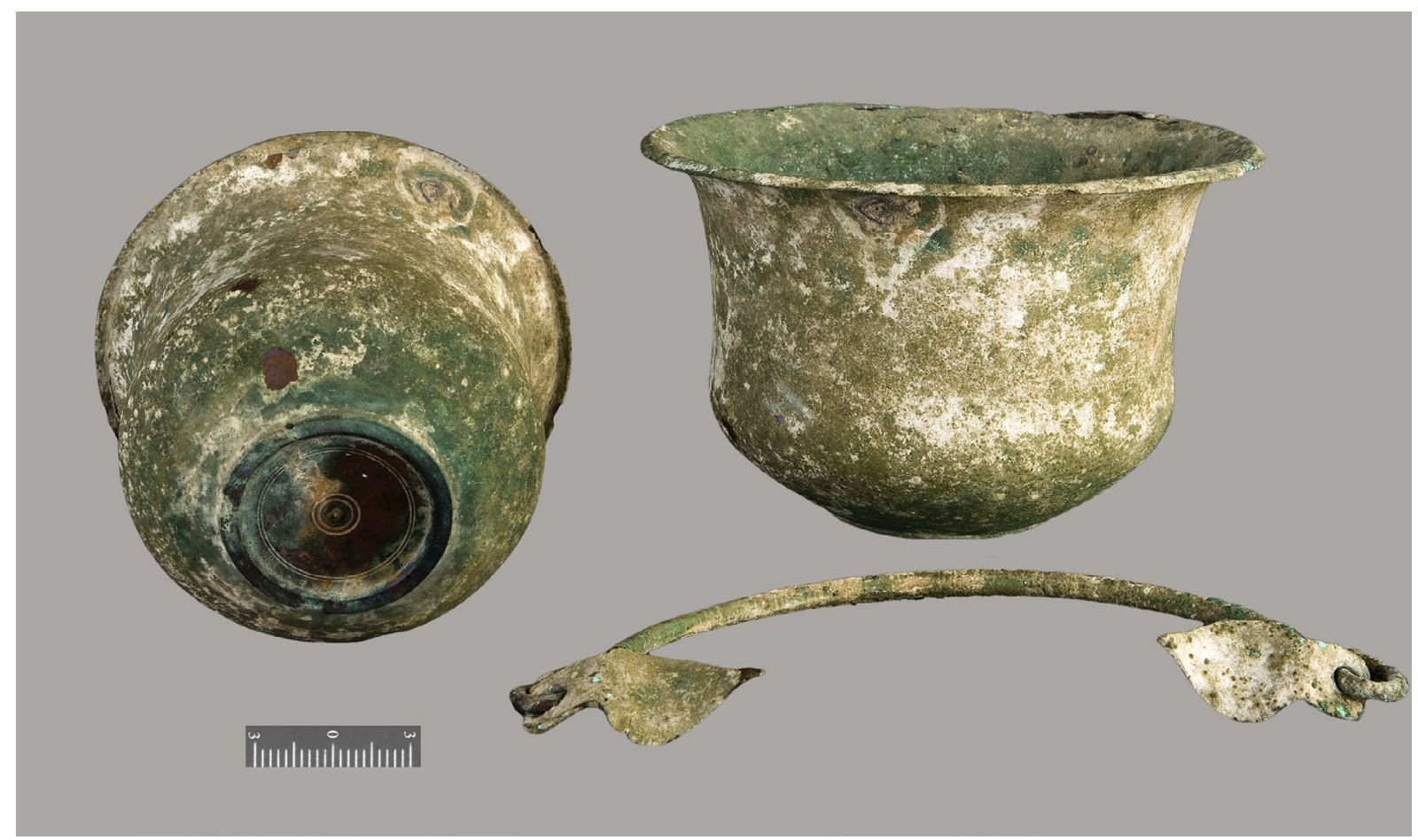

Figura 2. Sítula de bronce de Santa Fe de Mondújar. Museo de Almería (cortesía del Museo de Almería).

dios centrados en las formas figurativas. Pero como se deduce de recientes recopilaciones sobre objetos metálicos pertenecientes al instrumentum domesticum de Hispania, este tipo de apliques debió ser muy frecuente además de $-\mathrm{o}$ precisamente por ello- asequibles (Aurrecoechea, 2009, p. 341, fig. 7, p. 344). Su sencillez - con formas triangulares o bien redondeadas y acorazonadas que recuerdan mucho a las hojas de hiedra- dificulta una clasificación más precisa. Cabe señalar también el hecho de que su hallazgo asociado al cuerpo de la sítula y, también, al conjunto de sestercios y dupondios altoimperiales permite adelantar la cronología de este tipo de apliques como han apuntado otros autores (Aurrecoechea, 2009, p. 343).

Este pequeño recipiente tiene una función o uso distinto a las sítulas más grandes empleadas en la cocina o para transportar el agua, por lo que en este caso hay que relacionarlo con el servicio de mesa o del vino (Wielowiejski, 1973, pp. 32-34). Es frecuente su hallazgo conjunto con diversos jarros, formando servicio como recipiente para mezclar el vino con otros líquidos. El tipo viene definido en primer lugar por sus dimensiones, inferiores a lo habitual, con una altura que oscila entre $11 / 19 \mathrm{~cm}$ mientras el diámetro de la abertura se sitúa entre los $18 / 27 \mathrm{~cm}$. Su perfil es más o menos acampanado de paredes cóncavas y abombamiento en la zona inferior. El pie anular es bajo y estrecho, borde resaltado y exvasado de labio corto y oblicuo. Los apliques inferiores del asa suelen ser lisos (hojas cuoriformes) o ricamente ornados con motivos figurados en relieve. Las paredes del vaso van decoradas con parejas de ranuras incisas y son realizadas mediante fusión plena con retoques al torno y buril. Nuestra sítula almeriense encaja en este modelo que se corresponde con el Tipo XI, 57 Radnóti (1938, pp. 124-125, lám. XXXVI, 5-6), a su vez equivalente con el 152 den Boesterd (1956, pp. 46-47, lám. VI) y el 35 Raev (Typ Balčik) (1977, pp. 628, lám. 33,2 lám.15,5 y 7 lám. 20,2 lám. 24,3 lám. 28,1-2), cuya data se sitúa entre los siglos II-III d. C. No obstante, su asociación al conjunto de bronces altoimperiales ya citado, apunta a la segunda mitad del siglo II d. C.

Una variante -paredes lisas, fundición plena- es aquella cuyos recipientes realizados mediante martilleado de una fina lámina de metal con retoques de buril y cincel, con paredes que presentan acanaladuras onduladas -generalmente- o bien diferentes motivos geométricos: rombos entrecruzados, puntas de flecha, láureas, etc. Es el Tipo XXXIV, 2-4 Radnóti (1938, pp. 121-122, lám. XXXI, 2-4), 51 Eggers (1951, p. 55, lám. 6), 15 Raev (1977, pp. 628-630 lám. 34.1). La forma está ausente en el repertorio de las ciudades vesubianas lo que contribuye a situar su producción mayoritariamente entre el siglo II y principios del 


\begin{tabular}{|c|c|c|}
\hline Núm. & Lugar del hallazgo & Observaciones \\
\hline \multicolumn{3}{|c|}{ Hispania } \\
\hline 1 & Santa Fe de Mondújar (Almería) & \\
\hline $2-3$ & Villanueva del Trabuco (Málaga) & Acanalada \\
\hline $4-5$ & Utrera (Sevilla) & \\
\hline 6 & Cerro del Minguillar (Baena, Córdoba) & \\
\hline 7 & Alcolea del Río (Sevilla) & \\
\hline 8 & Bolonia (Cádiz) & \\
\hline 9 & Villanueva de Río y Minas (Sevilla) & \\
\hline 10 & Villanueva de Córdoba (Córdoba) & \\
\hline 11 & Tarragona (Tarragona) & \\
\hline 12 & San Silvestre (Assafarga, Coimbra) & \\
\hline \multicolumn{3}{|c|}{ Germania } \\
\hline 13 & Bijland (Tolkamer, Países Bajos) & \\
\hline 14 & $\begin{array}{l}\text { Maguncia (Renania-Palatinado, } \\
\text { Alemania) }\end{array}$ & \\
\hline 15 & Heidenheim (Baviera, Alemania) & \\
\hline \multicolumn{3}{|c|}{ Norico } \\
\hline 16 & Wagna (Estiria, Austria) & \\
\hline 17 & Salzburgo (Austria) & \\
\hline 18 & Enns (Alta Austria) & \\
\hline \multicolumn{3}{|c|}{ Panonia } \\
\hline 19 & Oggau (Burgenland, Austria) & \\
\hline $20-21$ & Pölöske (Zala, Hungría) & \\
\hline 22 & Novi Banovci (Novi Banovci, Serbia) & \\
\hline 23 & Stari Slankamen (Vojvodina, Serbia) & \\
\hline 24 & Budapest (Hungría) & \\
\hline 25 & Györ (Hungría) & Acanalada \\
\hline 26 & Albertfalva (Hungría) & Acanalada \\
\hline 27 & Szöny (Kamárom, Hungría) & Acanalada \\
\hline \multicolumn{3}{|c|}{ Moesia } \\
\hline 28 & Balcik (Dobruja, Bulgaria) & \\
\hline 29 & Varna (Bulgaria) & \\
\hline \multicolumn{3}{|c|}{ Tracia } \\
\hline $30-31$ & Sofía (Bulgaria) & \\
\hline $32-33$ & Stara Zagora (Bulgaria) & \\
\hline 34 & Kaloyanovets (Bulgaria) & \\
\hline 35 & Sliven (Bulgaria) & \\
\hline 36 & Pomorie (Bulgaria) & \\
\hline \multicolumn{3}{|c|}{ Dacia } \\
\hline 37 & Zlatna (Rumania) & \\
\hline \multicolumn{3}{|c|}{ Dalmacia } \\
\hline $38-39$ & Starigrad (Croacia) & acanalada \\
\hline 40 & Croacia & acanalada \\
\hline \multicolumn{3}{|c|}{ Galia - Italia } \\
\hline 41 & Marnay (Franco-Condado, Francia) & \\
\hline 42 & $\begin{array}{l}\text { Chatenoy-en-Bresse (Borgoña, } \\
\text { Francia) }\end{array}$ & \\
\hline 43 & Lyon (Ródano-Alpes, Francia) & \\
\hline 44 & Tienen/Tirlemont (Brabante, Bélgica) & acanalada \\
\hline
\end{tabular}

\begin{tabular}{|c|c|c|}
\hline Núm. & Lugar del hallazgo & Observaciones \\
\hline 45 & Pont-Croix (Bretaña, Francia) & $\begin{array}{l}\text { Con moneda } \\
\text { de Galieno y } \\
\text { Claudio II }\end{array}$ \\
\hline 46 & Apt (Provenza, Francia) & \\
\hline 47 & Chalain-d'Uzore (Loira, Francia) & \\
\hline 48 & Milán (Lombardía, Italia) & \\
\hline \multicolumn{3}{|c|}{ Moesia } \\
\hline 49 & Smocan (Bulgaria) & acanalada \\
\hline \multicolumn{3}{|c|}{ Siria-Palestina } \\
\hline 50 & Tell Oum Hauran (Siria) & \\
\hline 51 & Palestina (Museo de Ontario) & \\
\hline \multicolumn{3}{|c|}{ Barbaricum } \\
\hline 52 & Topolno (Gmina Pruszcz, Polonia) & acanalada \\
\hline 53 & Zerbst (Sajonia-Anhalt, Alemania) & acanalada \\
\hline 54 & Oldenburg (Baja Sajonia, Alemania) & acanalada \\
\hline 55 & Öremölla (Schonen, Suecia) & acanalada \\
\hline 56 & Brunsberg (Noruega) & acanalada \\
\hline 57 & Gunderupgaard (Dinamarca) & acanalada \\
\hline 58 & Kalö (Dinamarca) & acanalada \\
\hline 59 & Brokjär (Dinamarca) & acanalada \\
\hline 60 & Mercado anticuario (Subastas Lofty) & \\
\hline
\end{tabular}

Tabla 1. Procedencia y características destacables de los hallazgos citados en el texto.

s. III d. C. La relativa uniformidad del modelado en los abundantes hallazgos de las provincias danubianas (Panonia, Nórico), región del Mar Negro (Moesia y Tracia) y Dalmacia, permite situar en dicha región los centros productores (Raev, 1977, p. 628; Bónis, 1978, pp. 118-121; Szabó, 1980, pp. 715-728). Igualmente se atestiguan hallazgos, aunque en menor número, en las provincias romanas de Galia, Germania e Hispania, siendo mucho menos frecuentes en la pars orientis: Siria, Judea... En sentido contrario sobresalen los hallazgos en el Barbaricum.

\subsection{LAS SítUlAS DE BRONCE DE ÉPOCA IMPERIAL PROCE- DENTES DE Hispania}

Un repaso a las principales publicaciones sobre sítulas hispanas, permite comprobar la menor representación de aquellas con forma acampanada como la que nos ocupa con respecto a las bitroncocónicas (Erice, 2007, pp. 210-211, fig. 3), aunque debe tenerse en cuenta el reducido número de ejemplares que han llegado hasta nosotros completos o, al menos, en un estado de conservación suficiente para su correcta catalogación. Asas y apliques de sujeción al cuerpo del recipiente 
son con frecuencia los únicos elementos conservados, y solo en contadas ocasiones una parte del cuerpo y borde permiten una identificación más precisa.

No obstante, en Hispania se documentan varias sítulas -en sus dos variantes- que constituyen buenos paralelos para el ejemplar de Santa Fe de Mondújar (Fig. 3; Tab. 1). La mayor parte de estos recipientes proceden de la antigua provincia Baetica: Del Cortijo de las Beatas (Villanueva del Trabuco, Málaga) (Pozo, 1999-2000, pp. 244-247, figs. 4-5) proceden dos sítulas, la primera de paredes lisas con parejas de finas ranuras en el centro y zona inferior del cuerpo $(\mathrm{H}$ $11,30 \mathrm{~cm}$; D. abertura 15,60 cm) (Fig. 4.1), el borde exvasado y labio fino entrecortado por una sucesión de festones. Además, conserva el asa (sogueada) rematada en sendas cabezas ornitomorfas (cisnes o anátidas), de modelado muy esquemático y geométrico. La segunda pieza ha perdido el asa (H 11,20 cm; D. $16,80 \mathrm{~cm}$ ) (Fig. 4.2) y muestra las paredes ornadas con motivos geométricos: sucesión de rombos, puntas de flecha, bandas verticales y una láurea bajo el borde. El hallazgo se asocia a un oenochoe (paradero actual desconocido) del tipo 68 Radnóti, un jarro tipo B 1241Tassinari, una pátera umbilical con mango del tipo 29 Radnóti, una cacerola de la forma 25 Radnóti (Radnóti, 1938, pp. 79, 86, 146, láms. VI, 25, 29 y XII, 68; Tassinari, 1993, láms. B 1241, D 2400, H 2300) y una lucerna broncínea, bylichnis, con asa ricamente figurada (máscara de Pan), variante del tipo con volutas Mahdia (Iványi, 1935, nº 248, lám. LIX, XXX). Todos los recipientes se conservan en la Hispanic Society of America (New York) y formaban parte de la colección de bronces antiguos de D. Antonio Vives y Escudero (Madrid), que se vendió parcialmente al anticuario G. Meunière (Paris) (Mélida, 1900; García-Bellido y García-Bellido, 1993).

Otros dos ejemplares proceden de Utrera (Sevilla) (H $11 \mathrm{~cm}$; D. 17,50 cm; H 12 cm; D. $19 \mathrm{~cm}$ ) (Fig. 4.34) ${ }^{2}$ y están fabricados a partir del martilleado de una fina lámina de metal. Un ejemplar completo, fue encontrado junto con otros muchos objetos arqueológicos (Castillo y Ruiz-Nicoli, 2008, p. 153) durante las excavaciones realizadas a comienzos del siglo $\mathrm{XX}$ por el erudito baenense D. Francisco Valverde y Perales en el Cerro del Minguillar (Baena, Córdoba), lugar donde se ubica la antigua Iponoba (Morena López, 2013, p. 31). La sítula es de fundición plena con aplique inferior del asa que reproduce una hoja acorazonada. Conocemos también la procedente de Arva (Alcolea del Río, Sevilla) (H 21cm; D $28 \mathrm{~cm}$ ), conservada en

2 Inéditas. Museo Arqueológico de Sevilla n ${ }^{\circ}$ invt. RE1985/181 y RE1985/183. Donación Hurtado.

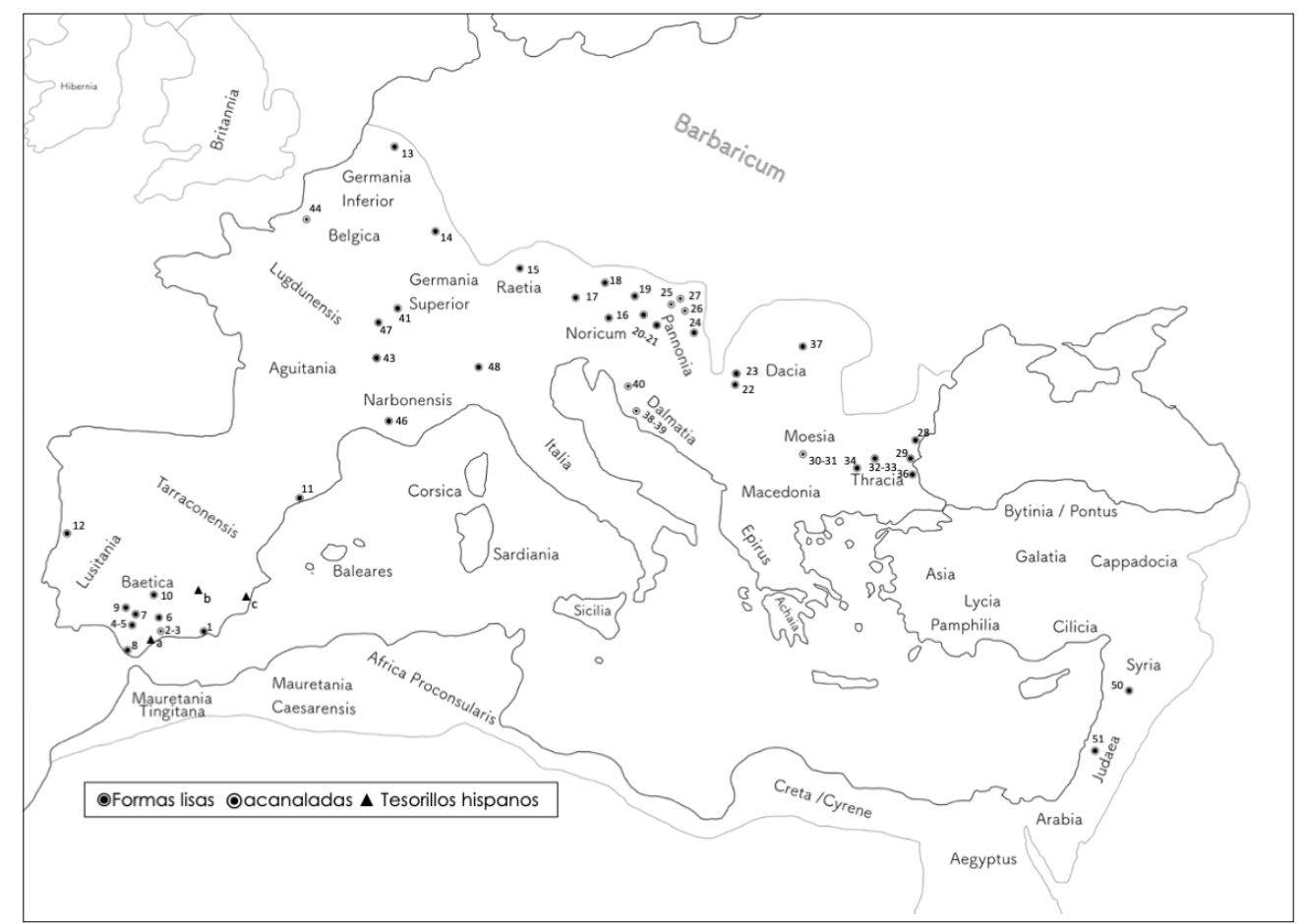

Figura 3. Ubicación de los hallazgos de sítulas en las provincias del Imperio, y de los ocultamientos hispanos relacionables con el de Almería: a. Rio Verde (Marbella), b. Riópar (Albacete), c Dianium (Alicante) (elaboración propia). 

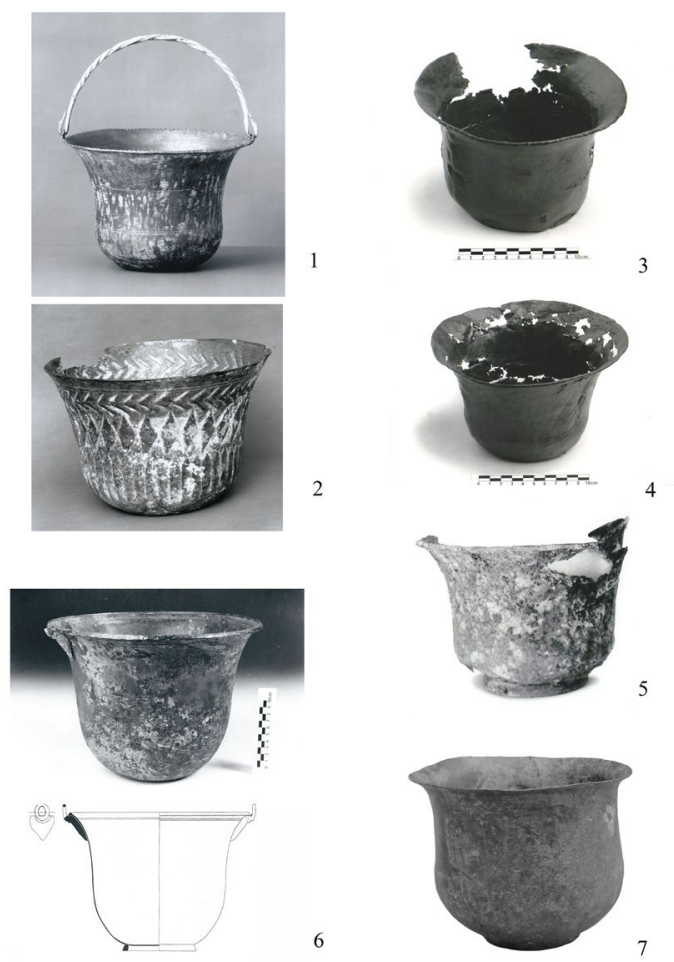

Figura 4. 1-2. Sítulas de Villanueva del Trabuco (Málaga). Hispanic Society of America (New York) (cortesía de D. Constantino del Álamo); 3-4. Sítulas de Utrera. Museo Arqueológico de Sevilla. Junta de Andalucía; 5. Sítula de Baelo Claudia (cortesía de la Casa de Velázquez. Madrid); 6. Sítula de Munigua (cortesía del Instituto Arqueológico Alemán de Madrid); 7. Sítula de Tarraco (Tarragona) (Roig 2003)

el Museo Arqueológico Nacional (nº invt. 1981/24/1). En este caso se trata de un cubo de fundición plena, con paredes lisas ornadas con ranuras y aplique inferior del asa en forma de hoja. Un recipiente exhumado en el curso de la undécima campaña de excavaciones de la Casa Velázquez en Baelo Claudia (Bolonia, Tarifa, Cádiz) (H 11,20 cm; D $15 \mathrm{~cm}$ ) (Fig. 4.5) (Sillières y Didierjean, 1977 pp. 520-521, lám. XXII, 2), apareció en el sector del macellum en un nivel de derribo junto a un jarro de bronce Tipo 76 Radnóti (Radnóti, 1938, p. 155, lám. L, 4 y 6). La sítula de Munigua (Villanueva de Río y Minas, Sevilla) (Vegas, 1984, p. 193, figs. 5-6, láms. 52b) es de mayor tamaño $(\mathrm{H}$ 23,20 cm; D. 29,20 cm) (Fig. 4.6), y se trata de un bronce pleno con aplique inferior del asa que adopta forma de hoja cuoriforme. Una sítula Tipo 20-22 de Eggers, hallada en Villanueva de Córdoba, presenta en este caso un sistema de sujeción de hierro, y como nota de interés contenía un tesorillo de 130 denarios romanos acuñados entre el 152 y 113-112 a. C. (Raddatz, 1969, p. 53; Chaves, 1996, p. 5; Pozo, 2000, pp.
433-434, no 24;). También se documenta esta forma en las provincias Tarraconense y Lusitania. Se trata de las sítulas de Tarraco (Tarragona) (H $19 \mathrm{~cm}$; D $25 \mathrm{~cm}$ ) (Fig. 4.7) (Roig, 2003, pp. 102-103, no 4.1. figs. 16 a-b) y de S. Silvestre (Assafarga, Coimbra) (Pereira, 1971, pp. 365-369).

\subsection{LOS PARALELOS EXTRAPENINSULARES}

Fuera de Hispania ${ }^{3}$ los hallazgos de esta forma de sítula son todavía más abundantes, pues como se ha apuntado más arriba sus principales centros de producción se sitúan en las provincias danubianas (Fig. 3; Tab. 1). Así contamos en Germania con los hallazgos de Bijland, entre Millingen y Lobith (Países Bajos) (H 11,90 $\mathrm{cm}$; D $17 \mathrm{~cm}$ ), conservado en el Museo de Nijmegen (Boesterd, 1956, pp. 46-47, nº 152, lám. VI), cuyo aplique del asa reproduce la efigie de una Medusa o Ménade en relieve. Se data entre los siglos II-III d. C., junto con el de Mogontiacum (Maguncia), conservado en el Römisch-Germanisches Zentralmuseum (Stümpel, 1976-1977, p. 297, fig. 46, II, 4); y el de Heidenheim (Baden-Württemberg) (Rabold, 1993, p. 40; 1994, p. 15, fig. 4).

En el Nórico conocemos los ejemplares de Flavia Solva (Wagna, Estiria) (H 8,20 cm; D 13,05 cm) (Mutz, 1972, p. 167, no 492; Sedlmayer, 1999, p. 105, lám. $47,1)$, procedente de una necrópolis y datado en el siglo II d. C; Iuvavum (Salzburgo) (H 14 cm; D 24 cm) (Silber, 1929, p. 1, no 2; Heger, 1974, p. 136, 218, fig. 139), con la misma data; Lauriacum (Enns) (H 11,60 cm; D $19,80 \mathrm{~cm}$ ) (Jenny, 1954, p. 76, fig. 37), datado en la primera mitad del s. III d. C. De Panonia pueden aducirse los siguientes paralelos: Oggau (Burgerland) $(\mathrm{H} \mathrm{9,70}$ cm; D 15,20 cm) (Pittioni, 1941, pp. 15-21, fig. 11); dos recipientes proceden de Pölöske (Hungría) (Radnóti, 1938, pp. 124-125, lám. XXXVI, 5-6), datados en el siglo II d. C.; Burgenae (Novi Banovci, Serbia) (Popovic et al., 1969, p. 126, $\mathrm{n}^{\circ}$ 226); de Acumincum (Stari Slankamen, Serbia) (Popovic et al., 1969, p. 126, $\mathrm{n}^{\circ}$ 226), procede una sítula de mayor tamaño (H $34 \mathrm{~cm}$; D $29 \mathrm{~cm}$ ) con aplique inferior del asa ornado con Erotes.

En Moesia conocemos los ejemplares de Dionysopolis (Balčik, Dobruja, Bulgaria) (Skorpil, 1912, p. 117, nº 17, fig. 92; Raev, 1977, p. 635, nº 4, lám. 33,2) y Odessos (Varna, Bulgaria) (Raev, 1977, p. 641, n $^{\circ}$ 94, lám. 24, 3). En Tracia: dos ejemplares de la necrópolis de Serdika (Sofía, Bulgaria) (H $8 \mathrm{~cm}$; H $14 \mathrm{~cm}$ ) (Ognenova, 1964, pp. 153-157, fig. 5; Raev, 1977, pp.

3 Agradecemos a la Dra. Klara De Decker (Westfälische Wilhelms-Universität Münster) la lectura de este trabajo, así como sus interesantes comentarios. 
628, 639, nº 69, lám. 15,7) exhumados en una tumba de fines del siglo III d. C.; otros dos de Ulpia Augusta Traiana (Stara Zagora, Bulgaria) (Bujukliev, 1973, pp. 38-45; Raev, 1977, p. 640, nº 80, lám. 20, 2; nº 74, lám. 28, 2) de finales del siglo II o inicios del siglo III d. C.; de Kalojanovec (Bulgaria) (Raev, 1977, p. 637, no 36, lám. 28, 1); de Sliven (Bulgaria) (Bacova, 1960, pp. 47-49; Raev, 1977, p. 639, nº 67, lám. 15, 5); y uno más de Anchialus (Pomorie, Bulgaria) (Raev, 1977, p. 639, no 58, lám. 26, 5). De Dacia: conocemos el ejemplar de Ampelum (Zlatna, Rumania) (Wollmann, 1996, p. 467, lám. 96).

Galia -e Italia- concentran igualmente un buen número de ejemplares, algunos paralelos cercanos a la sítula almeriense: de Marnay (Franco-Condado) (Bonnamour, 1978 p. 104, $\mathrm{n}^{\circ} 159$ ) procede un recipiente hallado junto al río Saona, con asa sogueada $\mathrm{y}$ paredes con acanaladuras onduladas. Contamos además con los ejemplares de Chatenoy-en-Bresse (Borgoña) (Baratte et al., 1984, nº 160); de Ludgunum (Lyon, Francia) (H 10,25 cm; D 14,80 cm) (Boucher y Tassinari, 1976, p. 129, n 150); de Tienen/Tirlemont (Brabante, Bélgica) (Mertens, 1952, pp. 51-54, láms. VI, 1, figs. 2, 5; Loë, 1937, p. 101, fig. 35), donde la excavación en una necrópolis tumular propició el hallazgo de una sítula con paredes decoradas (acanaladuras onduladas) y asa sogueada. Junto a la sítula se hallaron otros vasos metálicos: un oenochoe Tipo 72 Radnóti, una pátera umbilical con decoración en el fondo (episodio de la guerra de Troya) 27 Radnóti y un askos (Radnóti, 1938, pp. 82-83, lám. VI, 27; p. 147, lám. XII, 72); la sítula de Pont-Croix (Quimper, Bretaña) (Sanquer, 1973, p. 376, fig. 28) apareció en un contexto de destrucción datado en el siglo III d. C., asociada a monedas de Galieno y Claudio II; del Tesoro de Apt (Provenza) (Cavalier, 1988, p. 65, n 22-23) procede un recipiente sin pie anular datado en el siglo III d. C.; también de un hallazgo conjunto contamos con el recipiente de Chalain-d'Uzore (Loira, Francia) (Feugère, 1984-1985, p. 89, n 142); y de Mediolanum (Milán, Italia) proviene el conocido ejemplar recuperado en un pozo romano excavado en la Vía Lanzone (H 12 cm; D 21,20 cm) (Castoldi, 1986, pp. 209-213, figs. 1-4; Bolla, 1994, p. 59, nº 69, láms. LVIII-LIX). Pieza muy conocida, de fusión plena, paredes lisas con parejas de ranuras, presenta el borde entrecortado con muescas incisas y el aplique inferior decorado con una figura de Dyonissos en relieve. Igualmente se documenta una sítula argéntea con strigiles en la cara externa exhumada en la villa romana de Terzigno, Torre del Greco (Campania) (Cicirelli, 1989, p. 51, nº 6).

Por último, de las provincias orientales contamos con los ejemplares de la tumba 133 del Tell Oum Hauran (Siria) (H 11,50 cm; D 16 cm) (Hayes, 1984, p. 89, $\left.\mathrm{n}^{\mathrm{o}} 142\right)$, con aplique inferior del asa con decoración en relieve de una máscara de Dyonissos, que se data por los vidrios asociados al hallazgo en el siglo II d. C. También otro ejemplar hoy conservado en el Royal Ontario Museum de Toronto (Canadá), procede de Palestina (H 15,50 cm; D 12,50 cm) (Hayes, 1984, pp. 89-90, n 143).

Los recipientes con paredes decoradas con acanaladuras onduladas -Bronzeeimer mit gewundenen Kanneluren- (Willers, 1907, p. 49; Werner, 1936; 1939) reproducen el mismo perfil y tipo que las sítulas precedentes. Entre otros ejemplos aducimos los de Panonia Aquincum (Budapest) (Radnóti, 1938, p. 121, lám. XXXIV, 3-4; Szabó, 1999, p. 246, nº 1-2), Arrabona (Györ, Hungría) (Bíró, 1961, pp. 241, 246, figs. 4, 7; 7, 9, 1; Szabó, 1999, p. 250, n 3), Albertfalva (Hungría) (Szabó, 1999, pp. 244-246, fig. 2-7), Brigetio (Szöny, Hungría) (Szabó, 1999, p. 250, nº 4). En Dalmacia Argyruntum (Starigrad, Croacia) (Abramič y Colnago, 1909, pp. 61-63, no 1-2, fig. 22; Hoffiller, 1903-1904, pp. 119-120 sl. 64) dos pequeñas sítulas (H 9,70 cm; D 15,10 cm); y otro de un lugar impreciso de Croacia (Willers, 1907, p. 56, fig. 34; Radnóti, 1938, lám. XXXIV, 2; Popović et al., 1969, p. 127 $\mathrm{n}^{\circ}$ 230). En Moesia Smočan (Bulgaria) (Raev, 1977, pp. $629,639, n^{\circ} 68$, lám. 34, 1).

En territorio Barbaricum se han documentado numerosos hallazgos: Topolno (Gmina Pruszcz, Polonia), Zerbst (Sajonia-Anhalt, Alemania), Oldenburg (Baja Sajonia, Alemania) (Willers, 1907, pp. 53-55; Kunow, 1983); Öremölla (Schonen, Suecia), Brunsberg (Noruega) (Lindenberg, 1973; Willers, 1907, p. 49): Seeland, Jutlandia, (Willers, 1907, pp. 49-53), Gunderupgaard, Kalö y Brokjär (Dinamarca) (Willers, 1907, p. 51; Eggers, 1951, p. 55, lám. 6, tipo 51). Destaca en este grupo el tipo con acanaladuras onduladas, el menos frecuente en Hispania. Existen igualmente otros ejemplos reseñables en el Mercado de Antigüedades ${ }^{4}$.

\section{EL OCULTAMIENTO MONETARIO: DOCE SESTERCIOS Y DOS DUPONDIOS DE VESPA- SIANO A MARCO AURELIO}

El modesto conjunto monetario del paraje almeriense de Fuente del Rey, Mondújar, no desentona con lo que conocemos sobre la circulación monetaria de la moneda de bronce en Hispania durante el siglo II d. C., en especial en lo que concierne a los sestercios. No obstante, este hallazgo viene a llenar un importante vacío en diferentes territorios del sureste peninsular,

4 Web de subastas www.lofty.com (H 12,10 cm; D 15,20 cm) [consulta 22.12.2019] 


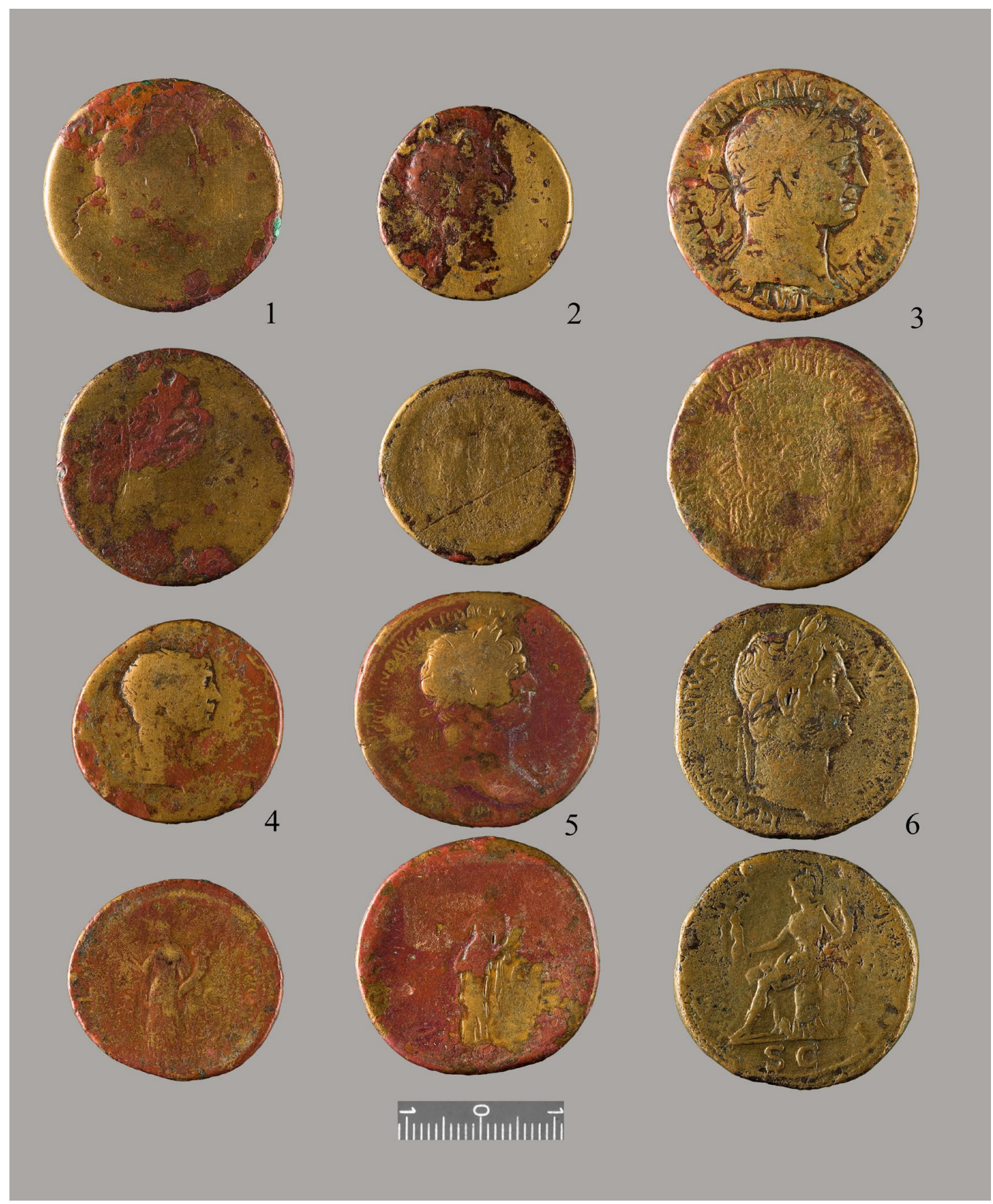

Figura 5. Dupondios y sestercios de Vespasiano, Trajano y Adriano de Santa Fe de Mondújar (cortesía del Museo de Almería).

sobre todo en la provincia de Almería, donde son muy escasos los testimonios numismáticos de este período (Tab. 2; Figs. 5 y 6 ).

Además de la testimonial presencia de un sestercio de Vespasiano: núm. inv. 1, prácticamente ilegible por su elevado desgaste como consecuencia de haber estado en circulación casi cien años, el mayor núme- ro de ejemplares, nueve, se reparte entre Trajano y Adriano, mientras que las emisiones de Antonino Pío -incluida aquí la moneda a nombre de Faustina I- y Marco Aurelio tienen una menor representación, con dos ejemplares cada uno. Aunque este desequilibrio no es extraño, solo en términos absolutos, en los hallazgos de circulación (Bost, Campo y Gurt, 1979, p. 
176; Arias Ferrer, 2007, pp. 409-410), no queda tan claro en los ocultamientos monetarios cuyo cierre no incluye monedas de Cómodo. Este es el caso del tesorillo de Riópar (Albacete) (Vidal, 1987-1988; Alberola, Sanz y Abascal, 2019) con 244 bronces donde las emisiones de Nerva, Trajano y Adriano representan un 70,9\% del conjunto, mientras que las monedas

\begin{tabular}{|c|c|}
\hline 1 & $\begin{array}{l}\text { Vespasiano. Sestercio. Roma. 71-73 d. C. RIC II²/1, págs. } \\
\text { 22-27. }\end{array}$ \\
\hline & $21,88 \mathrm{~g}, 32 \mathrm{~mm}, 12 \mathrm{~h}, \mathrm{MA} 85773$ \\
\hline 2 & Trajano. Dupondio. Roma. 103-111 d. C. Woytek 321b \\
\hline & $11,26 \mathrm{~g}, 27 \mathrm{~mm}, 12 \mathrm{~h}, \mathrm{MA} 85774$ \\
\hline 3 & Trajano. Sestercio. Roma. 103 d. C. Woytek $158 \mathrm{~b}$ \\
\hline & 24,08 g, $33 \mathrm{~mm}, 6 \mathrm{~h}, \mathrm{MA} 85777$ \\
\hline 4 & $\begin{array}{l}\text { Trajano. Dupondio. Roma. 103-111 d. C. [optimo principi] } \\
\text { Woytek pp. } 41-45,109 \text { ss. }\end{array}$ \\
\hline & 10,43 g, $27 \mathrm{~mm}, 6 \mathrm{~h}$, MA 85775 \\
\hline 5 & $\begin{array}{l}\text { Trajano. Sestercio. Roma. } 103-111 \text { d. C. [optimo principi] } \\
\text { Woytek pp. } 41-45,109 \text { ss. }\end{array}$ \\
\hline & $25,93 \mathrm{~g}, 32 \mathrm{~mm}, 6 \mathrm{~h}, \mathrm{MA} 85776$ \\
\hline 6 & Adriano. Sestercio. Roma. 124-127 d. C. RIC II ${ }^{2} / 3870$ \\
\hline & $27,95 \mathrm{~g}, 32 \mathrm{~mm}, 6 \mathrm{~h}, \mathrm{MA} 85781$ \\
\hline 7 & Adriano. Sestercio. Roma. 134 d. C. RIC II²/3 1636 \\
\hline & $22,75 \mathrm{~g}, 31 \mathrm{~mm}, 12 \mathrm{~h}, \mathrm{MA} 85778$ \\
\hline 8 & Adriano. Sestercio. Roma. 130-138 d. C. RIC II ${ }^{2} / 32288$ \\
\hline & $21,22 \mathrm{~g}, 31 \mathrm{~mm}, 6 \mathrm{~h}, \mathrm{MA} 85783$ \\
\hline 9 & Adriano. Sestercio. Roma. 130-138 d. C. RIC II $2 / 32398$ \\
\hline & $26,60 \mathrm{~g}, 31 \mathrm{~mm}, 6 \mathrm{~h}, \mathrm{MA} 85784$ \\
\hline 10 & Adriano. Sestercio. Roma. 130-138 d. C. RIC II ${ }^{2} / 32410$ \\
\hline & $23,36 \mathrm{~g}, 31 \mathrm{~mm}, 6 \mathrm{~h}, \mathrm{MA} 85785$ \\
\hline 11 & Antonino Pío. Sestercio. Roma. 150-151 d. C. RIC III 866 \\
\hline & $25,19 \mathrm{~g}, 33 \mathrm{~mm}, 10 \mathrm{~h}, \mathrm{MA} 85786$ \\
\hline 12 & Faustina I. Sestercio. Roma. post 141 d. C. RIC III 1127 \\
\hline & 20,70 g, $30 \mathrm{~mm}, 11$ h, MA 85782 \\
\hline 13 & Marco Aurelio. Sestercio. Roma. $164-165$ d. C. RIC III 904 \\
\hline & $22,74 \mathrm{~g}, 32 \mathrm{~mm}, 12 \mathrm{~h}, \mathrm{MA} 85780$ \\
\hline 14 & $\begin{array}{l}\text { Marco Aurelio. Sestercio. Roma. 172-173 d. C. RIC III } \\
1049 \text { var.- BMC } 1432 \text { var. }\end{array}$ \\
\hline & $22,29 \mathrm{~g}, 32 \mathrm{~mm}, 6 \mathrm{~h}, \mathrm{MA} 85779$ \\
\hline
\end{tabular}

Tabla 2. Inventario de las monedas de Santa Fe de Mondújar, ilustradas en las Figs. 5 y 6. de los Antoninos solo alcanzan el 16,8 \%. Estos datos podrían considerarse un interesante paralelo para el hallazgo almeriense, si no fuera por las serias dudas que plantea su composición real a partir del reciente y exhaustivo análisis de toda la información relativa a este importante hallazgo monetario (Alberola, Sanz y Abascal, 2019, pp. 270-271), quizá compuesto por más de 400 monedas, de las que una parte relevante -las mejor conservadas y más apreciadas por los coleccionistas-debieron corresponder a las emisiones de los Antoninos, puede que también de Cómodo.

En efecto, una composición más esperada es la que ofrecen otros ocultamientos hispanos. Pero ninguno procede de la Baetica, y además tienen una data de cierre claramente posterior al almeriense, entrada ya la primera mitad del siglo III d. C. Es el caso del tesorillo de 'El Mirador' (Alicante) (Abascal, Olcina y Ramón, 1995, pp. 9-11), en el entorno de Dianium, en el que además de la escasa presencia de moneda de época flavia $-2,59 \%$ - la aceptable representación de emisiones de Nerva a Adriano - 25,26\% \% queda muy por debajo de la moneda antonina. Se trata del conjunto más numeroso del ocultamiento con un $67,71 \%$, en el que sobresale tanto el elevado porcentaje de las emisiones de Marco Aurelio -un 30 \%-como la débil representación de la moneda de Cómodo, que no alcanza al $12 \%$. No obstante, lo alejado de los ejemplos aducidos con respecto al hallazgo almeriense y, sobre todo, lo reducido de la muestra que manejamos, no aconseja profundizar mucho en este asunto.

Volviendo a la composición del hallazgo de Santa $\mathrm{Fe}$ de Mondújar, los cuatro ejemplares de Trajano (núms. inv. 2-5) coinciden con las emisiones iniciadas en 103 d. C. y se concentran, como era de esperar, en las leyendas SPQR OPTIMO PRINCIPI vinculadas a las guerras dácicas (Chaves Tristán, 1993, pp. 111-112; Beckmann, 2012, p. 409), bien documentadas también entre los hallazgos hispanos (Arias Ferrer, 2007, pp. 572, 580, 595, etc.). La secuencia de sestercios de Adriano nuevamente resulta en parte la esperada, aunque dentro de las limitaciones de análisis que permite su reducido número. Es el caso de la ausencia de emisiones correspondientes a la primera fase de su reinado, de amplia difusión en Hispania. Por el contrario, sí que resulta esperable la concentración en torno las emisiones de los años 125-138 d. C. (núm. inv. 6, HADRIANVS AVGVSTVS / COS III), y, sobre todo, la que combina la inscripción HADRIANVS AVG COS III PP en anverso con reversos más comunes como los dedicados a Diana y a Fortuna Augusta (núms. inv. 9-10) (Beckmann, 2012, p. 413). También se constatan otros tipos menos frecuentes, como es el caso de las representaciones de Capadocia y Némesis (núms. inv. 7-8). 

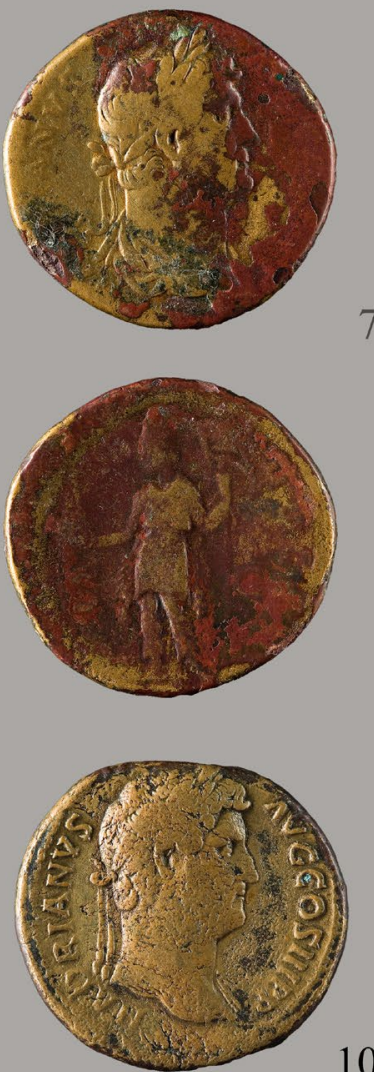

10
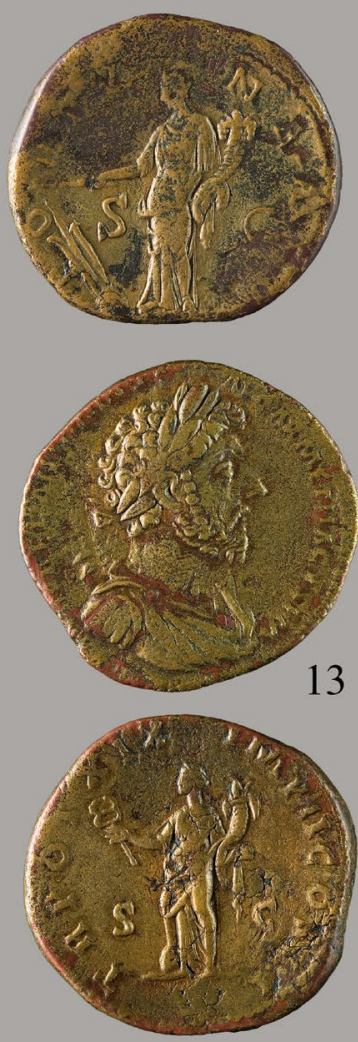
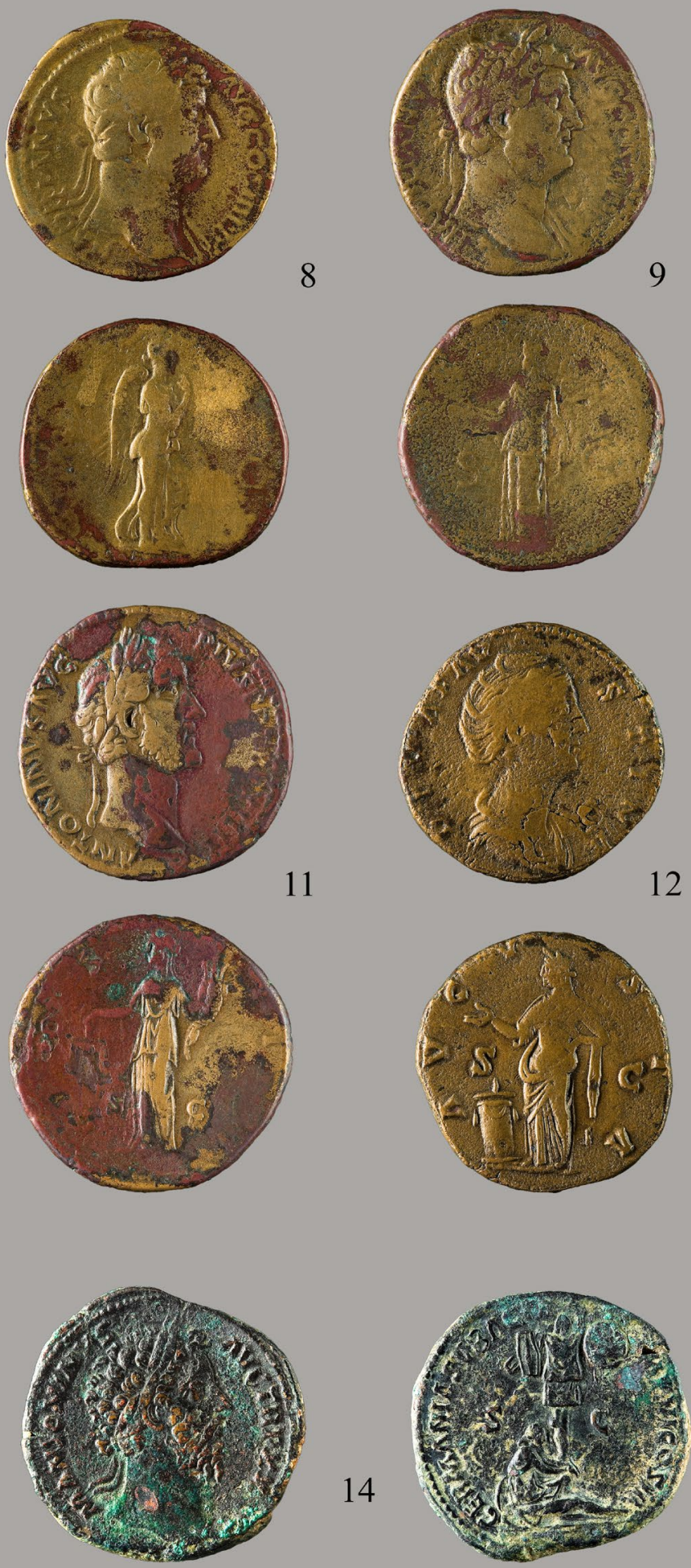

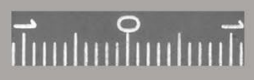

Figura 6. Sestercios de Adriano, Faustina I y Marco Aurelio de Santa Fe de Mondújar. Museo de Almería (cortesía del Museo de Almería). 
La moneda de los Antoninos está representada, como se ha dicho, por sestercios de Antonino Pío y Marco Aurelio, incluyendo uno dedicado a Faustina I: núm. inv. 12 de la emisión más frecuente con inscripción DIVA FAVSTINA // AVGVSTA (Pietas) en anverso y reverso, respectivamente. La del emperador se data entre los años 150-151 d. C.: núm. inv. 11, y no se trata en este caso de una serie representativa si la comparamos con otras posteriores a mediados de siglo que anticipan el incremento de producción durante el reinado de su sucesor Marco Aurelio (Yarrow, 2012, p. 425), pero que no refleja la composición del hallazgo almeriense. Los dos sestercios de este emperador pertenecen a la primera: núm. inv. $13,164-165$ d. C. y segunda fase de su reinado 172-173 d. C.: núm. inv. 14, de impacto diferenciado en la circulación monetaria de Hispania y desde luego en ocultamientos como el citado de Dianium (Abascal, Olcina y Ramón, 1995, p. 18). Pero con solo dos monedas no podemos valorar este aspecto ni otros como la incidencia-ausencia en nuestro caso- de las abundantes emisiones a nombre de Faustina II.

Por otra parte cabe plantearse también, a propósito de la distancia cronológica entre las dos emisiones de Marco Aurelio presentes en este modesto depósito o monedero (Arias Ferrer, 2007, p. 28), si el entorno del Bajo Andarax participaba ya de un empobrecimiento del numerario circulante, en cuanto a la llegada de moneda de refresco se refiere. El problema es que carecemos de hallazgos, ya sea de circulación o procedentes de ocultaciones en esta comarca, y en general en buena parte del territorio almeriense (Martínez y Muñoz, 1999, p. 265), con la parcial excepción de $B a$ ria (Villaricos) y su entorno, que nos permitan valorar si el que aquí analizamos refleja, siquiera aproximadamente, el panorama monetario de esta comarca entre la frontera sur de la Tarraconense y la oriental de la Bética a finales del siglo II d. C.

En efecto, como ya se ha apuntado son todavía muy escasas las referencias a hallazgos numismáticos recientes de esta y otras comarcas almerienses; una falta de datos que se agrava de forma especial para el período altoimperial. Confiando en que futuros descubrimientos procedentes de trabajos de excavación o prospección en enclaves con protección arqueológica modifiquen este panorama, una vía interesante de estudio es el acceso -no siempre fácil- a algunas colecciones locales en las que todavía tiene sentido utilizar el término de "hallazgos fortuitos o casuales" (Rodríguez Temiño, 2015, p. 217). Un ejemplo reciente, aunque algo alejado del entorno de nuestro hallazgo, es el del término municipal de Abla, antigua Albathal Alba (Padilla Arroba, 2016, pp. 112, 128) de donde proceden varios bronces del período que nos ocupa, en concreto sestercios de Trajano (RIC 523), Adriano (RIC 832), Antonino Pío (RIC 605) y Lucio Vero (RIC 1309). Estas monedas se suman a las recopiladas por Arias Ferrer (2007, p. 577) procedentes de Adra (Abdera) -sestercio de Trajano-, Chirivel -sestercios de Trajano y Marco Aurelio- y Fiñana -sestercio de Antonino Pío-.

De uno de estos lugares, Las Juntas (Abla), procede también un as de Adriano (RIC 832) (Padilla Arroba, 2016, p. 112 núm. 4). Esta moneda nos sirve de pretexto para insistir en el carácter selectivo que en general tienen los atesoramientos, ya se trate de sumas modestas o no, y el que nos ocupa no es una excepción. En estos momentos de la segunda mitad del siglo II d. C., el as y en mayor medida el dupondio todavía juegan un papel destacado en la masa monetaria circulante hasta el reinado de Marco Aurelio (Harl, 1996, p. 95), como se aprecia en Hispania tanto en yacimientos béticos (Bost y Chaves, 1987, p. 68; Chaves, 1979, pp. 78,82 ) como en el sur de la Tarraconense (Arias, 2006, pp. 50-52). La presencia de dos dupondios -núms. inv. 2 y 4- junto a las otras doce monedas de Santa Fe de Mondújar insisten en ello y no resulta, además, algo excepcional en otros ocultamientos monetarios de época altoimperial como el de Rio Verde (Marbella) (Mora, 1999-2000, p. 132) con un as/dupondio y el de Riópar (Albacete) con siete dupondios y un medallón (Alberola, Sanz y Abascal, 2019, pp. 270-271). Deben incluirse también aquí los cerrados en el primer tercio de la centuria siguiente (Arias, 2007, pp. 820 ss.).

No obstante, el sestercio es ya en estos momentos de la segunda mitad del siglo II d. C. el nominal más apreciado, y en muchos yacimientos y territorios hispanos presenta porcentajes que se acercan al cincuenta por ciento del total de la moneda de bronce emitida en ese período (Bost, Campo y Gurt, 1979, pp. 189-190; Ripollès, 2002, p. 204). En este sentido, y aunque los hallazgos recopilados para estos momentos en los territorios almerienses son del todo insuficientes para obtener conclusiones fiables al respecto, es cierto que el número de sestercios es superior al de ases o dupondios, como igualmente comprobamos en el Valle del Almanzora (Fontenla, 2007, p. 261). Sería prudente contemplar aquí la variable topográfica en cuanto a la composición de este modesto depósito, en el sentido de la probable sobrerrepresentación del sestercio sobre ases y dupondios en ambientes rurales -esto es, más alejados del modelo de circulación urbana- apuntada para diferentes puntos de la Tarraconense (Lledó, 2007, p. 302).

Pero no conviene olvidar, en un sentido contrario, la situación del lugar de procedencia de este hallazgo, próximo a una de las más destacadas vías de comunicación de la región como es la que comunicaba la costa con Urci y Acci, para luego conectar con el golfo de 
Almería y el Portus Magnus (Álvarez Martín, 2013, pp. 58-61). No es posible valorar por el momento si la constatada relación entre las vías de comunicación y la mayor presencia de moneda en los asentamientos urbanos y rurales de su entorno, tema bien estudiado en los últimos años (Mora, Centeno y García-Bellido, 1999), ha podido mediatizar la formación de este modesto ocultamiento monetario.

En cuanto a la data de la posible ocultación del conjunto de monedas y el recipiente de bronce, es razonable proponer los años finales del siglo II d. C., pues dado que la datación de la sítula no aporta como hemos visto mayor precisión -siglos II-III d. C.-, es el desgaste de las monedas y la siempre cuestionable, aunque útil, observación sobre la presencia y ausencia de determinadas emisiones - de moneda de Cómodo en nuestro caso-, lo que nos puede acercar más al momento en el que estas monedas fueron retiradas de circulación junto con el recipiente que las contenía. En este sentido debe tenerse en cuenta el buen estado de conservación de los dos sestercios de Marco Aurelio -sobre todo del segundo: inv. 13 (RIC III 904) y 14 (RIC III 1049)- que cierran el conjunto, y cuya data $c a .171-172 \mathrm{~d}$. C. propone un terminus post quem para su ocultación en la década de los años setenta u ochenta del siglo II d. C. Lógicamente no puede descartarse un momento algo posterior, a pesar del escaso desgaste que presenta la moneda más reciente, sobre todo teniendo en cuenta que en estos momentos se inicia un descenso en el aprovisionamiento de moneda de bronce que se hace visible en el reinado de su sucesor Cómodo. Los datos que se conocen, tanto para el conjunto de Hispania (Bost, Campo y Gurt, 1979, p. 177; Ripollès, 2002, p. 205), como en especial en el sureste peninsular (Arias Ferrer, 2006, p. 46) así lo corroboran. No obstante, recordemos que para el territorio de donde procede nuestro hallazgo, situado en la trasterra del Golfo de Almería, la información sobre su circulación monetaria es tan escasa como insuficiente, sobre todo en lo que concierne a la moneda de bronce de época antonina.

De obligado comentario en el estudio de los ocultamientos monetarios es preguntarse por las posibles causas que hicieron que sus propietarios no pudieran recuperarlos. Alguno de los citados aquí como el de Riópar son buena muestra de ello, pero al mismo tiempo también de los riesgos que supone una aplicación, puede que forzada en algún caso, de la relación entre guerra y ocultamientos o atesoramientos no recuperados. Para el caso hispano tenemos varios ejemplos de revisión, a la baja, de estas asociaciones, como son el conflicto sertoriano (Rodríguez Casanova, 2009) y las razias germanas del siglo III d. C. (Campo y Gurt, 1980, p. 129). Así, la relación con las incursiones de los mauros en el sur peninsular durante el reinado de Marco Aurelio - ca. 171-172 /177-180 d. C.- se han puesto en relación, especialmente la segunda, con el depósito albaceteño antes citado (Vidal, 1987-1988, pp. 149-152), si bien la posibilidad de que contuviera moneda de Cómodo plantea serias dudas al respecto (Alberola, Sanz y Abascal, 2019, pp. 272-273), al igual que la aparente lejanía del lugar del hallazgo con el escenario, impreciso, en el que se desarrollaron estas incursiones.

No obstante, si para la primera de las incursiones las fuentes hablan de desórdenes generalizados en varias provincias hispanas, incluida Lusitania, en una relación para algunos autores con una fuerte carga propagandística que no tiene un reflejo claro en la documentación arqueológica (Bernard, 2009, p. 360), la segunda incursión ca. 177-180 d. C. cuenta con dos famosos testimonios epigráficos en Italica (Santiponce, Sevilla) -CIL II 1120- y Singilia Barba (Antequera, Málaga) -CIL II2/ ${ }^{5}, 783-$. Sin profundizar aquí en la mayor o menor trascendencia de este segundo ataque, puede que también magnificado, parece consensuado que el desarrollo de esta última incursión se debió centrar en la provincia Baetica (Bernard, 2009, p. 373). A propósito de la inscripción singiliense, la combinación de factores geoestratégicos como su posición en el eje Malaca-Antikaria, o la posible relación entre los mauri y la tribu de los Maurensioi, en el norte de la Tingitana, aunque de localización imprecisa, ha planteado la posibilidad de que esta segunda incursión tuviera como epicentro la región malacitana, bien conectada como sabemos con la costa africana del mar de Alborán y su principal puerto de Rusaddir (Melilla) (Rodríguez Oliva, 1984; Bernard, 2009, pp. 372-373). La fácil comunicación de esta vía con el interior bético bien pudo favorecer las razias de estos mauri, con las que se han relacionado algunos ocultamientos monetarios como el integrado por $30 \mathrm{de}-$ narios de Augusto a Antonino Pío procedente de Castro del Río, Córdoba (López Medina, 2016, pp. 236-237).

Tampoco tenemos evidencias de que las incursiones mauras llegaran al sureste peninsular, aunque precisamente la ambigua noticia de dos ocultamientos monetarios en Paulenca y Moscolux (Cara y Carrilero, 1987 p. 65), pertenecientes al municipio almeriense de Gádor, ha planteado esta posibilidad, pero con muchas reservas. Lo cierto es que nada sabemos de estos tesorillos, que por otro lado parecen asociarse a asentamientos tardorromanos (López Medina, 2004, pp. 146-147).

Como en otros muchos casos, es arriesgado pronunciarse por las causas que propiciaron el ocultamiento monetario de Santa Fe de Mondújar, aunque un dato relevante en este sentido es la presencia de la sítula en cuyo interior se encontraban, según afirmó en su día su descubridor, las catorce monedas de bronce 
que venimos comentando. Como ya se ha apuntado más arriba, resulta infrecuente y por tanto extraño el uso de vajilla metálica como contenedor en hallazgos monetarios de las características y época que nos ocupa. La sítula de bronce, sin duda con un valor muy superior a las catorce monedas que se guardaban en ella, parece indicar que se trata de una ocultación de emergencia, puede que incluso ajena al propietario del asentamiento al que se asocia, pues se echa en falta la presencia de moneda de oro o plata, o bien una cantidad mayor de numerario de bronce, e incluso de otros vasos metálicos como hemos visto en otros hallazgos hispanos y extrapeninsulares.

La ausencia de control arqueológico impide aclarar esta y otras incógnitas de este hallazgo. Modesto, pero de no escaso interés, abunda en la afirmación inserta en una de las primeras recopilaciones sistemáticas sobre hallazgos monetarios antiguos en el territorio almeriense: “... observamos el lugar secundario que ocupan las costas almerienses en los textos, no siempre justificado por la arqueología" (Pérez Casas, 1978, p. 303).

\section{BIBLIOGRAFÍA}

Abascal, J. M., Olcina Domenech, M. y Ramón Sánchez, J. (1995). Un tesoro de sestercios romanos procedente del Territorium de Dianium (Hispania Citerior). Alicante: Museo Arqueológico de Alicante.

Abramić, M. y Colnago, A. (1909). "Untersuchungen in Norddalmatien". Jahreshefte des Österreichischen Archäologischen Instituts, 12, pp. 12-112.

Alberola Belda, A., Sanz Gamo, R. y Abascal Palazón, J. M. (2019). El tesorillo de monedas romanas de Riópar. Albacete: Instituto de Estudios Albacetenses.

Álvarez Martín, E. (2013). "Las vías de comunicación entre Guadix y Almería a través del Pasillo de Fiñana en época ibérica". Arqueología y Territorio, 10, pp. 57-71.

Arias Ferrer, L. (2006). La circulación monetaria en el Levante peninsular durante el siglo II $d$.C. Villena: Fundación Municipal José María Soler.

Arias Ferrer, L. (2007). La circulación monetaria en la Hispania del siglo II d.C. Historia y evolución de la Península Ibérica a través de la documentación numismática. Universidad de Alicante.

Aurrecoechea Fernández, J. (2009). "Vajilla metálica de época romana en la región central de Hispania (CC. AA. de Madrid y Castilla-La Mancha)". Sautuola, XV, pp. 327-348.

Bacova, E. (1960). "Trouvailles archéologiques de Sliven et ses environs". Archeologija Sofia, 2, pp. 47-49.

Baratte, F., Bonnamour, L., Guillaumet, J.- P. y Tassinari, S. (1984). Vases antiques de métal au Musée de Chalon-sur-Saône. Dijon: Revue archéologique de l'Est et du Centre-Est, $5^{\mathrm{e}}$ Supplément.

Beckmann, M. (2012). "Trajan and Hadrian". En: Metcalf, W.E., ed., The Oxford Handbook of Greek and Roman Coinage. Oxford: Oxford University Pres, pp. 405-422.
Bernard, G. (2009). "Les prétendues invasions maures en Hispanie sous le règne de Marc Aurèle: essai de synthèse". Pallas, 89 , pp. 357-375.

DOI: https://doi.org/10.4000/pallas.15391

Bíró, E (1961). "Györ-Nádorvárosi kora császárkori sírok. Frühkaiserzeitliche Gräber in Györ-Nádorváros", Archaeologiai Értesitö, 89, pp. 240-248.

$\mathrm{BMC}=$ Mattingly, H. (2005). Coins of the Roman Empire in the British Museum. IV. Antoninus Pius to Commodus. London: Spink.

Boesterd, M. H. P. den (1956). Description of the collection in the Rijksmuseum G. M. Kam at Nijmegen. Nijmegen: Rijksmuseum.

Bolla, M. (1994). Vasellame romano in bronzo nelle Civiche Raccolte Archeologice di Milano. Notizie dal Chiostro del Monastero Maggiore, Supplemento, 11. Milano: Civiche raccolte archeologiche e numismatiche di Milano.

Bónis, E. B. (1978). "Rekonstruktionsversuche aus dem Fundinventar des Römerzeitlichen Bestattungswagens von Szomor-Sodomorpuszta". Folia Archeologica, 29, pp. 103-121.

Bonnamour, L. (1978). "Les vases antiques trouvés dans la Saône". Dossiers d'Archéologie, 28, pp.32-41.

Bost, J.-P., Campo, M. y Gurt, J. M. (1979). "La circulación monetaria en Hispania durante el período romano-imperial: problemática y conclusiones generales". En: I Simposium Numismático de Barcelona, II. Barcelona: Societat Catalana d'Estudis Numismàtics, pp. 174-202.

Bost, J.-P. y Chaves, F. (1987): "Le Haut-Empire romain (27 av. J.-C. - 192 ap. J.-C.)". En: Bost, J.-P., Chaves, F., Depeyrot, G., Hiernard, J. y Richard, J.-C. (1987). Belo IV. Les monnaies. Madrid: Casa de Velázquez.

Boucher, S. y Tassinari, S. (1976). Bronzes antiques du Musée de la Civilisation Gallo-Romaine à Lyon. Lyon: Musée de la civilisation gallo-romaine - Boccard.

Bujukliev, Chr. (1973). "Thrakijski mogilni poghrebenija ot okolnostite na Stara Zagora, Archeologija Sofija". Archeologičeski Institut i Muzej, XV, pp. 38-45.

Campo, M. y Gurt, J. M. (1980). "El problema de la crisis del s. III: su reflejo en los hallazgos monetarios realizados en la costa catalana y las Baleares". Numisma, 30, pp. 165-167.

Cara, L. y Carrilero, M. (1987). "Prospección arqueológica superficial del estuario del Andarax y piedemonte de la Sierra de Gádor (Almería)". Anuario Arqueológico de Andalucía 1985, II, Sevilla: Junta de Andalucía, pp. 63-66.

Castillo, E. y Ruiz-Nicoli, B. (2008). "Iponuba y su conjunto escultórico de época Julio-Claudia". Romula, 7, pp. 149-186.

Castoldi, M. (1986). "Il secchiello di Via Lanzone". En: Scritti in ricordo di Graziella Massari Gaballo e di Umberto Tocchetti Pollini. Milano: Edizioni ET, pp. 209-213.

Cavalier, O. (1988). Le trésor d'Apt: un ensemble de vaisselle métallique gallo-romaine. Avignon: Fondation du Muséum Calvet.

Chaves Tristán, F. (1979). “Avance sobre la circulación monetaria en Itálica”. I Simposium Numismático de Barcelona, Vol. I. Barcelona, 77-86. 
Chaves Tristán, F. (1993). "Amonedación de Trajano". En: González, J. (Ed.). IMP. CAES. NERVA TRAIANVS $A V G$. Sevilla: Ediciones Alfar, pp. 87-135.

Chaves Tristán, F. (1996). Los tesoros en el sur de Hispania: Conjuntos de denarios y objetos de plata durante los siglos II y I a.C. Sevilla: Fundación El Monte.

Cicirelli, C. (1989). "Le ville romane di Terzigno, Torre del Greco". Rivista di Studi Pompeiani, III, pp. 249-252.

CIL II = Hübner, E. (1869). Corpus Inscriptionum Latinarum. Berlin: Berlin-Brandenburgische Akademie der Wissenschaften.

CIL II ${ }^{2} / 5$ = Stylow, A. U., Atencia Páez, R., González Fernández, J., González Román, C., Pastor Muñoz, M. y Rodríguez Oliva, P. (1998). Corpus Inscriptionum Latinarum. Volumen Secundum. Inscriptiones Hispaniae Latinae. Pars VII: Conuentus Cordubensis, Berlin: Berlin-Brandenburgische Akademie der Wissenschaften.

Corzo Sánchez, R. y Toscano San Gil, M. (1992). Las vías romanas de Andalucía. Sevilla: Consejería de Obras Públicas y Transportes.

Delgado, M. (1970). "Elementos de situlas de bronze de Conimbriga". Conimbriga, 9, pp.16-41. DOI: https://doi.org/10.14195/1647-8657_9_3

Eggers, H. J. (1951). Der römische Import im Freien Germanien. Atlas der Urgeschichte. I. Hamburg: Hamburgisches Museum für Völkerkunde und Vorgeschichte.

Erice, R. (2007). "La vajilla de bronce en Hispania". En: Metalisteria de la Hispania Romana, Sautuola, 13, pp. 197-215.

Feugère, M. (1984-1985). "Le trésor de Chalain-d'Uzore (Loire)". Cahiers Archéologiques de la Loire, 4/5, pp. 35-70.

Fontenla Ballesta, S. (2007). Circulación monetaria en el valle del Almanzora (Almería): edades antigua y media. Lorca: Fajardo El Bravo.

García Bellido, A. y García-Bellido, M. ${ }^{a}$ P. (Eds.) (1993). Álbum de dibujos de la colección de bronces antiguos de Antonio Vives Escudero. Anejos de Archivo Español de Arqueología, XIII. Madrid: Editorial CSIC.

Gorecki, J. (1991). "Überlegungen zu römischen Münzschatzbehältnissen. Ein archäologischen Phänomen. Mit einer Übersicht metallener Hortgefäße in den Nordwest-und Donauprovinzen". En: Noeske, H. Ch. y Schubert, H. (Eds.). Die Münze - Bild -Botschaft -Bedeutung. Festschrift für Maria R. Alföldi, Frankfurt am Main: Peter Lang, pp. 203-233.

Gozalbes, M. y Torregrosa, J. M. (2014). "De Iberia a Hispania. Plata, dracmas y denarios entre los siglos VI y I a.C.". Archivo de Prehistoria Levantina, 30, pp. 275-316.

Harl, K. W. (1996). Coinage in the Roman Economy, 300 B.C. to A.D. 700. Baltimore-London: The John Hopkins University Press.

Hayes, J. W. (1984). Greek, Roman and related Metalware in the Royal Ontario Museum. Toronto: Royal Ontario Museum.

Heger, N. (1974). Salzburg in römischer Zeit. Salzburg: Salzburger Museum Carolino Augusteum.
Hoffiller, V. (1903-1904). “Antikne bronsane posude iz Hrvatske i Slavonije u Narodnom Muzeju u Zagrebu”. Vjesnik Arheološkog muzeja u Zagrebu, 7.1, pp. $98-123$.

Iványi, D. (1935). Die pannonischen Lampen. Eine typologische-chronologische Übersicht, Dissertationes Pannonicae, ser. II, 2. Budapest: Sárkány-Nyomda.

Jenny, W. A. (1954). "Graben VIII und Haus der Bronzegefässe". Forschungen in Lauriacum, 2, pp. 31-77.

Kunow, J. (1983). "Römisches Importgeschirr in der Germania libera bis zu den Markomannenkriegen. Metall- und Glasgefässe". Aufstieg und Niedergang der römischen Welt, 2, 12, 3, pp. 229-279.

Lindenberg, I. (1973). "Die Einfuhr römischer BronzegefäBe nach Gotland”. Saalburg Jahrbuch. Bericht des Saalburg Museums, XXX, pp. 4-69.

Lledó Cardona, N. (2007). La moneda en la Tarraconense mediterránea en época romana imperial. Valencia: Diputación de Valencia. Servicio de Investigación Prehistórica.

Loë, Baron de (1937). Belgique ancienne. Catalogue descriptif et raisonné, III. La période romaine. Musée Royaux d'Art et d'Histoire à Bruxelles, Bruxelles.

López Medina, M. J. (2004). Ciudad y territorio en el sureste peninsular durante la época romana. Madrid: Ediciones Clásicas.

López Medina, M. a J. (2016). "El conjunto de denarios altoimperiales de La Polonia (Castro del Río, Córdoba)". Lucentum, XXXV, pp. 227-243.

DOI: https://doi.org/10.14198/lvcentvm2016.35.13

Martínez López, C. y Muñoz Muñoz, F. A. (1999). Poblamiento ibérico y romano en el sureste peninsular: La Comarca de los Vélez (Almería). Granada: Editorial Universidad de Granada.

Mélida, J. R. (1900). "La colección de bronces antiguos de D. Antonio Vives". Revista de Archivos Bibliotecas y Museos, IV, pp. 27-32, 70-76, 154-164, 351-354, 404410, 541-546, 624-627, 649-651.

Mertens, J. (1952). "Une riche tombe gallo-romaine, découverte à Tirlemont (Belgique)". L'Antiquité Classique, 21.1, pp. 51-54. DOI: https://doi.org/10.3406/antiq.1952.3202

Mora, G., Centeno, R. M. S. y García-Bellido, M. ${ }^{\mathrm{a}}$ P. (Coords.) (1999). Rutas, ciudades y moneda en Hispania: Actas del II Encuentro Peninsular de Numismática antigua. Anejos de Archivo Español de Arqueología, XX. Madrid: Editorial CSIC.

Mora Serrano, B. (1999-2000). "Notas sobre un depósito de sestercios altoimperiales procedente de la villa romana de Río Verde (Marbella, Málaga)". Mainake, XXI-XXIII, pp. 129-138.

Morena López, J. A. (2013). "El cerro de Minguillar y la antigua ciudad de Iponoba (Baena)”. Itvci, 3, pp. 29-51.

Mutz, A. (1972). Die Kunst des Metalldrehens bei den Römern. Basel-Stuttgart: Basel Birkhäuser.

Ognenova, L. (1964). "Sépultures de la nécropole de Serdice mis à jour dans la rue Benkovsky, in Serdika". $M a$ tériaux et Recherches Archéologiques, 1, pp. 153-157. 
Ortiz Ocaña, A. J. (2016). "Las vías de comunicación de Alba”. En: Ortiz Ocaña, A. J. (Coord.). El municipio romano de Alba (Abla-Almería). Almería: Instituto de Estudios Almerienses, pp. 79-101.

Padilla Arroba, A. (2016). "Una aproximación al estudio de la moneda y la circulación monetaria en la ciudad púnica y romana de Abla ( 'lbt' /Municipium Alba)". En: Ortiz Ocaña, A. J. (Coord.). El municipio romano de Alba (Abla-Almería). Almería: Instituto de Estudios Almerienses, pp. 103-136.

Pereira, M. A. H. (1971). "Situla com inscrição encontrada em S. Silvestre, Assafarge". En: Actas do II Congresso Nacional de Arqueologia. Coimbra: Junta Nacional da Educação, pp. 365-369.

Pérez Casas, J. A. (1978). "Apuntes para el estudio económico de Almería en época romana: algunos cepos y monedas aparecidos en la costa". Cuadernos de Prehistoria y Arqueología de Granada, 3, pp. 303-326.

Pittioni, R. (1941). "Römische Funde aus der Landschaft Burgerland, Reichsgau Niederdonau. 1. Ein römisches Steinkistenbrandgrab aus Oggau (Landkreis Eisenstadt)". Jahreshefte des Österreichischen Archäologischen Instituts, XXXIII, pp. 15-70.

Popović, Lj. B., - Mano-Zisi, Đ., - Veličković, M., - Jeličić, B., Antička bronza u Jugoslaviji 1844-1969 Beograd: Narodni muzej.

Pozo, S. (1999-2000). "Recipientes broncíneos malacitanos de época romana en The Hispanic Society of America (New York, U.S.A.)". Mainake, XXI-XXII, pp. 244-247.

Pozo, S. (2000). "La vajilla metálica -bronce y plata- tardorrepublicana en la provincia Baetica". En Thomas, R. (Ed.). Antike Bronzen. Werkstattkreise: Figuren und Geräte, Akten des 14. Internationalen Kongresses für Antike Bronzen in Köln, 21. bis 24. September 1999. Kölner Jahrbuch, 33. Berlin: Mann, pp. 417-434.

Rabold, B. (1993). "Ein römischer Bronzefund aus Heidenheim/Brenz", Archäologie in Deutschland, 2, pp. 40-41.

Rabold, B. (1994). "Ein 'Schmiedefund' aus der römischen Zivilsiedlung in Heidenheim, Brenz". Forschungen und Berichte zur Vor-und Frühgeschichte in BadenWürttemberg, 1, pp. 13-18.

Raddatz, K. (1969). Die Schatzfunde der iberischen Halbinsel vom Ende des dritten bis zur Mitte des ersten Jahrhunderts vor Chr. Berlin: De Gruyter.

Radnóti, A. (1938). Die römische Bronzegefässe von Pannonien, Dissertationes Pannonicae, ser. II, 6. Budapest: Institut für Münzkunde und Archäologie der P. Pázmány-Universität.

Raev, B. A. (1977). "Die Bronzegefäße der römischen Kaiserzeit in Thrakien und Mösien”. Bericht der RömischGermanischen Kommission, 58, pp. 605-642.

RIC III = Mattingly, H. y Sydenham, E.A. (1930). Roman Imperial Coinage, Vol. III from Antoninus Pius to Commodus. London: Spink.

Ripollès, P. P. (2002). "La moneda romana imperial y su circulación en Hispania". Archivo Español de Arqueologia , 75, pp. 195-214.

DOI: https://doi.org/10.3989/aespa.2002.v75.135
Rodríguez Casanova, I. (2009). "Tesoros sertorianos: nuevas perspectivas desde datos antiguos". En: Arévalo, A. (Ed.). Actas del XIII Congreso Nacional de Numismática. Moneda y Arqueología. Madrid-Cádiz: Museo Casa de la Moneda, pp. 337-352.

Rodríguez Temiño, I. (2015). "Coleccionismo y expolio arqueológico: los comienzos de una relación problemática". Cuadernos de Prehistoria y Arqueología de la Universidad de Granada, 25, pp. 211-256

Rodríguez Oliva, P. (1984). "Contactos entre las tierras malacitanas y el Norte de África en época Clásica”. En: Olmedo Jiménez, M., coord., España y el Norte de África. Bases históricas de una relación fundamental (Aportaciones sobre Melilla). Granada: Editorial Universidad de Granada, pp. 195-206.

Roig, J. F. (2003). "Els vasos de bronze del pou Cartanyà: l'aixovar sacre d'un temple de l'antiga Tarraco". Revista d'arqueologia de Ponent, 13, pp. 83-124.

Sanquer, R. (1973). Circonscription de Bretagne: Ille-et-Vilaine, Morbihan, Côtes-du-Nord, Finistère. Paris: CNRS.

Sedlmayer, H. (1999). Die römischen Bronzegefässe in Noricum. Monographies Instrumentum, 10. Montagnac: Mergoil.

Silber, M. (1929). Fund einer römischen Bronze-Kanne in Salzburg. Salzburger Museumsblätter, 8. Salzburg.

Sillières, P. (1990). Les voies de communication de l'Hispanie Méridionale. Paris: Boccard.

Sillières, P. y Didierjean, F. (1977). "La onzième campagne de fouilles de la Casa de Velazquez à Belo en 1976 (Bolonia, province de Cadix)". Mélanges de la Casa de Velázquez, XIII, pp. 483-527. DOI: https://doi.org/10.3406/casa.1977.2259

Skorpil, K. (1912). "Grabfund in Balcik". Jahreshefte des Österreichischen Archäologischen Institutes in Wien, XV, pp. 101-134.

Stümpel, B. (1976-1977). "Bericht des Staatlichen Amtes für Vor-und Frühgeschichte Mainz für die Zeit vom 1. Januar 1974 bis 31. Dezember 1975". Mainzer Zeitschrift, 71/72, pp. 281-297.

Szabó, K. (1980). "Vaisselles de bronze sur la frontière pannonienne (entre Vetus Salina et Lussonium)". En: Hanson, W.S. y Keppie, L. J. F. (Eds.). Roman Frontier Studies: Papers presented to the International Congress of Roman Frontier Studies. BAR 71. II. Oxford: Archaeopress, pp. 715-728.

Szabó, K. (1999). "Un seau d'Albertfalva”. Budapest Régiségei, 33, pp. 243-263.

Tassinari, S. (1993). Il vasellame bronzeo di Pompeii. Roma: L'Erma di Bretschneider.

Vegas, M. (1984). "Munigua. Haus 6. Datierende Funde aus dem Räumen und aus dem Brunnen". Madrider Mitteilungen, 25, pp. 181-196.

Vidal, J. M. (1987-1988). "El tesoro de bronces imperiales de Riópar (Albacete)". Acta Numismática, 17-18, pp. 143-152.

Villaronga, L. (1993). Tresors monetaris de la Península Ibèrica anteriors a August: repertori i anàlisi. Barcelona: Asociación Numismática Española. 
Werner, J. (1936). "Zur Herkunft und Zeitstellung der Hemmoorer Eimer und der Eimer mit gewellten Kannelüren". Bonner Jahrbücher, 140-141, pp. 395-410.

Werner, J. (1939). "Ein Bronzeeimer mit gewellten Kanneluren von Eining". Germania, 23, pp. 192-194.

Wielowiejski, J. (1973). "Bemerkungen über die Verteilung der Funde und die Funktion der römische Metallgefässen in Mittel-und Osteuropa". Archeologia Warszava, 23, pp. 22-36.

Willers, H. (1907). Neue Untersuchungen über die römische Bronzeindustrie von Capua und Niedergermanien. Hannover-Leipzig: Hahn.
Wollmann, V. (1996). Mineritul metalifer, extragerea sării şi carierele de piatră în Dacia romană: Der Erzbergbau, die Salzgewinnung und die Steinbrüche im römischen Dakien. Bibliotheca Musei Napocensis 13. Cluj-Napoca.

Woytek, B. (2010): Die Reichsprägung des Kaisers Traianus (98-117). Moneta Imperii Romani, 14. Vienna: Österreichischen Akademie der Wissenschaften.

Yarrow, L. M. (2012). "Antonine Coinage". En: Metcalf, W. E. (Ed.). The Oxford Handbook of Greek and Roman Coinage. Oxford: Oxford University Press, pp. 423-452. 